\title{
Neutron spectra measurement and calculations using different data libraries in iron benchmark assembly
}

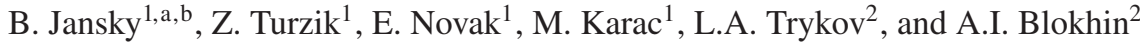 \\ 1 Nuclear Research Institute Řež plc, Czech Republic \\ 2 Institute of Physics and Power Engineering, Obninsk, Russia
}

\begin{abstract}
The leakage neutron spectra measurements have been done on benchmark spherical assembly - iron sphere with diameter of $100 \mathrm{~cm}$. The Cf-252 neutron sources with different emissions were placed into the centre of iron sphere. The proton recoil method was used for neutron spectra measurement using stilbene crystals and hydrogen proportional counters. The neutron energy range of spectrometer was from 0.01 to $17 \mathrm{MeV}$. The gamma pulse shape discrimination (PSD) method has been applied in stilbene measurements. The adequate MCNP neutron spectra calculations based on different data libraries (ENDF/B-VI.8, BROND-3, JENDL-3.3, JEFF-3.1) have been done and compared with measurements. Some aspects of presented benchmark are discussed in details including reproducibility of measurements, influence of group structure, smoothing of spectra, energy resolution of spectrometer, methodology of calculation (1- or 3-dimensional problem, results uncertainties), methodology of experiment (neutron background measurement using shadow cone). The results of analogous measurements and calculations performed on pure iron spheres of diameters 20,30 and $50 \mathrm{~cm}$ are also briefly discussed in the report.
\end{abstract}

\section{Introduction}

Neutron and gamma fields parameters behind iron and water layers corresponding to reactor pressure vessel were studied on benchmark iron spherical assemblies with diameter of 20, 30,50 and $100 \mathrm{~cm}$, and on water spherical assemblies with diameter 30 and $50 \mathrm{~cm}$. The $\mathrm{Cf}-252$ neutron sources were placed into the centre of iron sphere.

In this article the results of the leakage neutron spectrum measurement from the largest sphere of $100 \mathrm{~cm}$ diameter are presented, because of the discrepancies between calculation and experiment are the most significant.

The measurement results are compared with parallel calculations using four different data libraries in MCNP code. The following data libraries were used: ENDF/B-VI, BROND-3, JENDL-3.3, JEFF-3.1.

In the following text the libraries are usually marked by shorted name ENDF, BROND, etc.

The measurement results can serve as integral verification of various data libraries.

\section{Experimental assembly}

The experimental assemblies is formed by the pure iron sphere with diameter of $100 \mathrm{~cm}$ with neutron source in centre, see figure 1.

Neutron spectra were measured in two distances:

- $\mathrm{R}=150 \mathrm{~cm}$, abbrev. of assembly is FE DIA100, R150, shadow cone used (background is subtracted), spectrum measured by stilbene and $\mathrm{H}$-detector.

${ }^{a}$ e-mail: jan@ujv.cz

${ }^{b}$ NRI Rez plc, 25068 Husinec Rez, Czech Republic

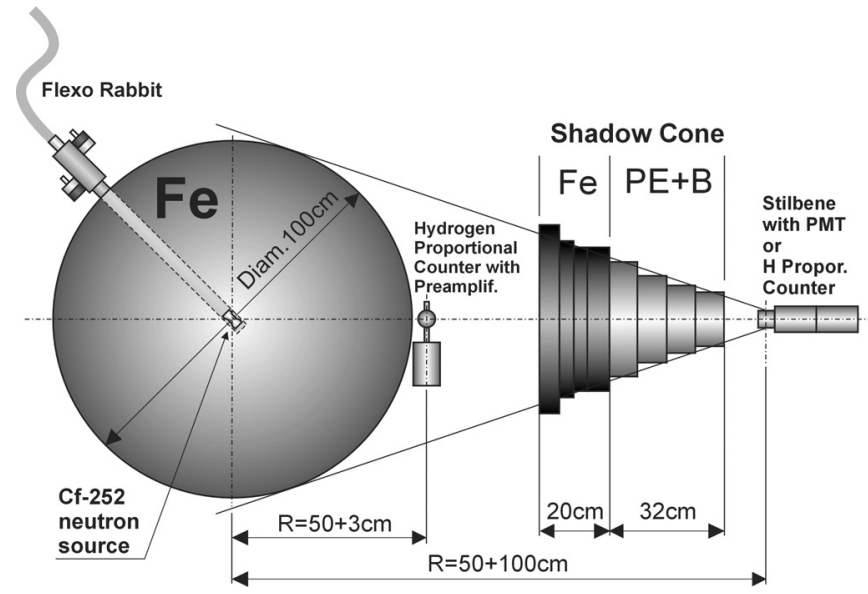

Fig. 1. Basic scheme of n-spectrum measurement. The sphere center is $200 \mathrm{~cm}$ above the concrete floor.

- $\mathrm{R}=53 \mathrm{~cm}$, abbrev. of assembly is FE DIA100, R53, shadow cone not used, (background is included), spectrum measured only by $\mathrm{H}$-detector.

\section{Methodology of calculation and measurement}

The spherical shape of assemblies and spherical neutron source is used because this geometry represents the most simple one-dimensional (1D) calculation task. As a matter of fact, the assembly is a $3 \mathrm{D}$ object.

The methodological 3D test-calculations (for Fe sphere of diam. $50 \mathrm{~cm}$ ) was carried out and compared with simplified $1 \mathrm{D}$ results. The differences are not significant.

The background of the measured field is determined by additional measurement performed with shielding cone. 


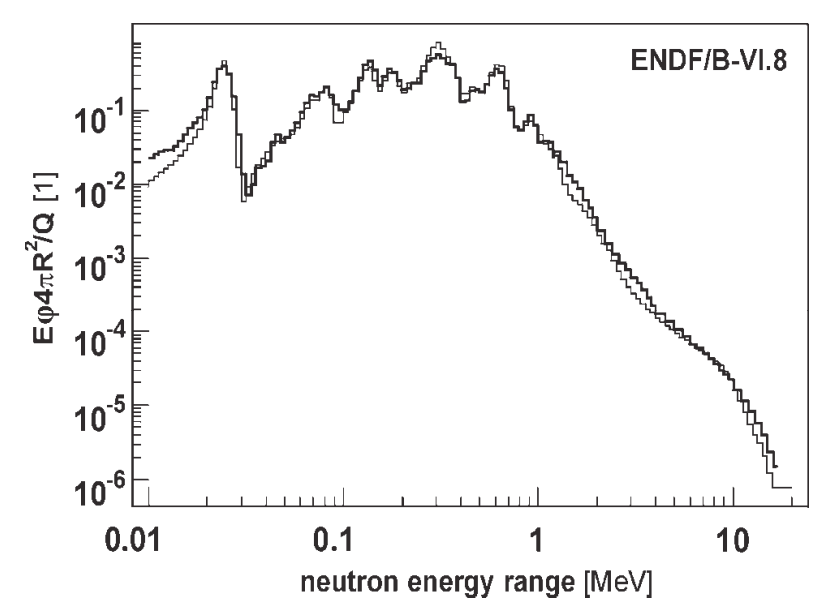

Fig. 2. Assembly: FE DIA100, R150, 40 gpd. Measurement by H-det and stilbene - thick. Calculation by ENDF/B-VI.8 - thin.

The shielding cone has to shield corresponding space angle to measure all unwelcome scattered neutrons and laboratory background neutrons.

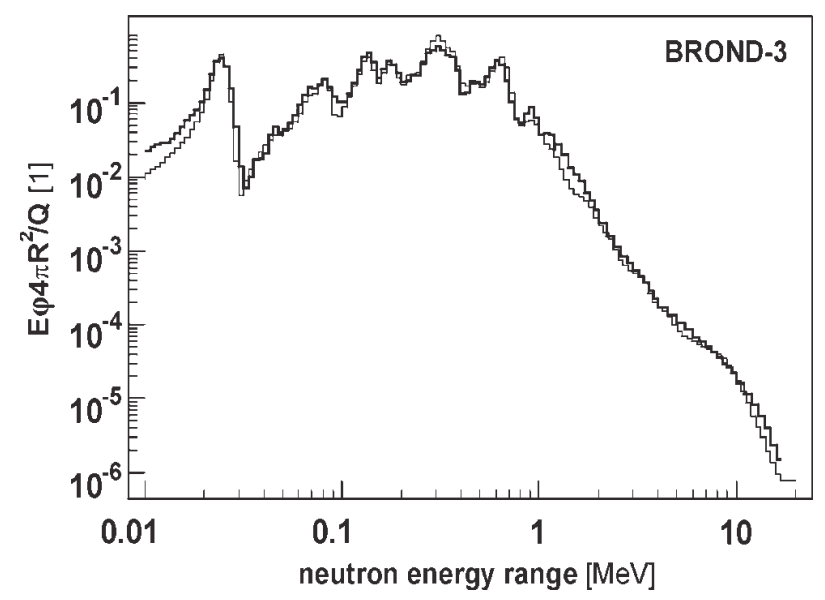

Fig. 3. Assembly: FE DIA100, R150, 40 gpd. Measurement by H-det and stilbene - thick. Calculation by BROND-3 - thin.

\section{Neutron spectrometers}

The proton recoil method was used for neutron and gamma spectra measurement as well as main methods. Hydrogen proportional counters $(0.01-1.3 \mathrm{MeV})$ and scintillation detector of stilbene $(0.1-17 \mathrm{MeV})$ [1], were used for neutron spectra measurement in the total energy range of $0.01-17 \mathrm{MeV}$. The group structure used for H-detector is 40 or 200 groups per decade (gpd). The group structure used for stilbene is the constant energy step in selected energy regions. Spherical hydrogen detectors were of $4 \mathrm{~cm}$ diameter and of 100, 400 and $1000 \mathrm{kPa}$ pressure. The dimension of stilbene was of diameter $3 \times 1 \mathrm{~cm}$.

\section{Calculation}

The calculations were performed using Monte Carlo program MCNP4c. As for geometry description, a simplified model [2]

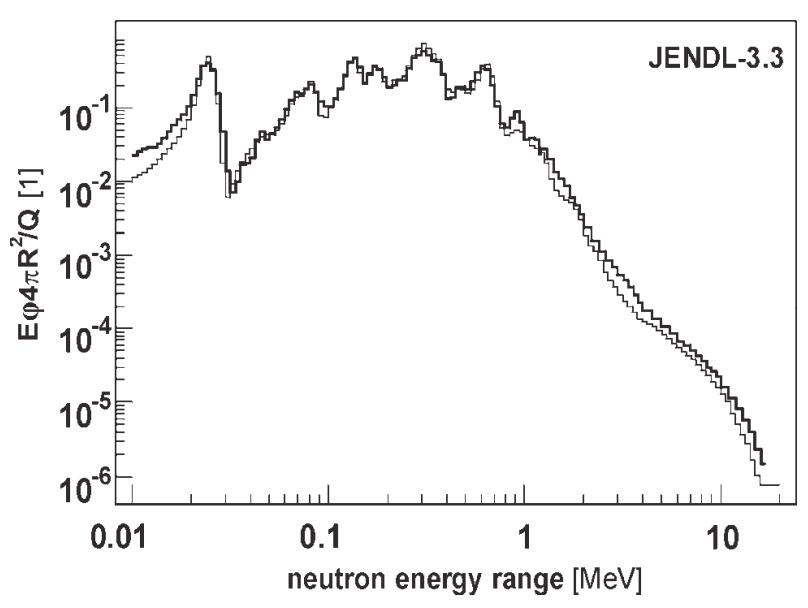

Fig. 4. Assembly: FE DIA100, R150, 40 gpd. Measurement by H-det and stilbene - thick. Calculation by JENDL-3.3 - thin.

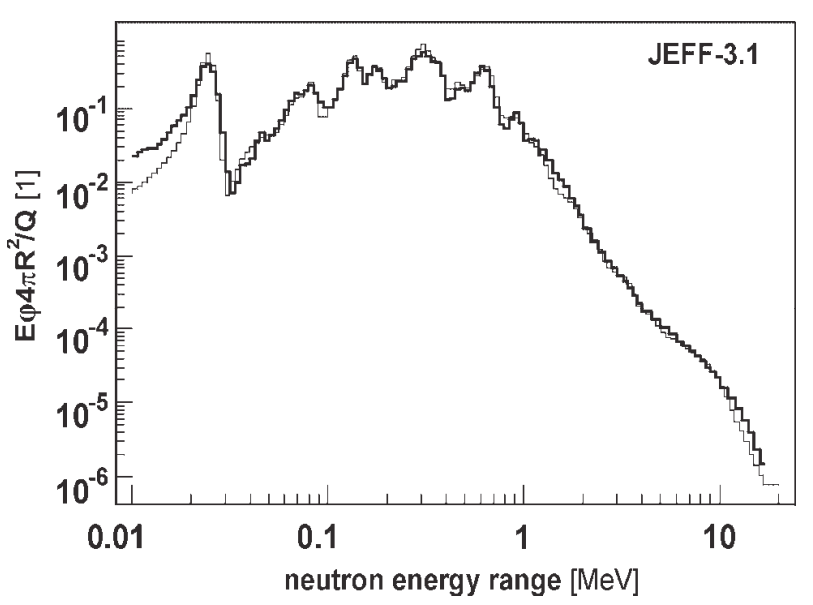

Fig. 5. Assembly: FE DIA100, R150, 40 gpd. Measurement by H-det and stilbene - thick. Calculation by JEFF-3.1 - thin.

was used, which substitutes assembly elements with concentric spherical shells around the source. Also, the detector is represented by a $1 \mathrm{~cm}$ thick spherical shell with radius equal to the real detector-source distance. In this way, considerable variance reduction has been achieved, while the results had remained essentially unperturbed in almost the whole energy range. Two detector shell radii have been dealt with: $53 \mathrm{~cm}$ (which, in the case of a $100 \mathrm{~cm}$ diameter sphere represents measurement of the spectrum close to the surface) and $150 \mathrm{~cm}$ (which represents distant measurement).

For each calculation, $10^{8}$ particle histories were computed. For JENDL library, $2 \times 10^{8}$ histories were calculated.

The energy bin structure of resulting tallies was chosen to be logarithmic, either with 40 or with 200 groups per decade. Photon tallies start at $0.001 \mathrm{MeV}$ and end at $12.59 \mathrm{MeV}$, while neutron tallies range from $10^{-10} \mathrm{MeV}$ to $22.39 \mathrm{MeV}$. However, only ten groups per decade scale are used up to $0.001 \mathrm{MeV}$. The following nuclear data libraries were used in calculation: ENDF/B-VI.8, BROND-3, JENDL-3.3, JEFF3.1. The evaluated nuclear data files were processed using NJOY99.115. 
Table 1. Assembly FE DIA100, R150; 40 gpd, H-det and stillbene measurement - integral values (energy range is in $\mathrm{MeV}$ ).

\begin{tabular}{cccccccc}
\hline \multicolumn{4}{c}{ Energy Range } & \multicolumn{3}{c}{ Libraries used for MCNP Calculation } \\
\hline No. & from & to & EXP & ENDF & BROND & JENDL & JEFF \\
\hline $\mathbf{0}$ & $\mathbf{0 . 0 1}$ & $\mathbf{1 7 . 0 0}$ & $\mathbf{8 . 3 9 7 E - 0 1}$ & $\mathbf{8 . 5 5 6 E - 0 1}$ & $\mathbf{8 . 4 5 9 E - 0 1}$ & $\mathbf{8 . 4 0 9 E - 0 1}$ & $\mathbf{8 . 7 9 6 E - 0 1}$ \\
\hline $\mathbf{1}$ & $\mathbf{0 . 0 1}$ & $\mathbf{0 . 0 3}$ & $1.289 \mathrm{E}-01$ & $1.115 \mathrm{E}-01$ & $1.105 \mathrm{E}-01$ & $1.131 \mathrm{E}-01$ & $1.210 \mathrm{E}-01$ \\
$\mathbf{2}$ & $\mathbf{0 . 0 3}$ & $\mathbf{0 . 1 0}$ & $9.592 \mathrm{E}-02$ & $8.575 \mathrm{E}-02$ & $8.296 \mathrm{E}-02$ & $8.934 \mathrm{E}-02$ & $8.969 \mathrm{E}-02$ \\
$\mathbf{3}$ & $\mathbf{0 . 1 0}$ & $\mathbf{0 . 1 5}$ & $1.112 \mathrm{E}-01$ & $9.619 \mathrm{E}-02$ & $9.608 \mathrm{E}-02$ & $1.056 \mathrm{E}-01$ & $1.156 \mathrm{E}-01$ \\
$\mathbf{4}$ & $\mathbf{0 . 1 5}$ & $\mathbf{0 . 2 0}$ & $8.359 \mathrm{E}-02$ & $7.546 \mathrm{E}-02$ & $7.465 \mathrm{E}-02$ & $7.965 \mathrm{E}-02$ & $8.424 \mathrm{E}-02$ \\
$\mathbf{5}$ & $\mathbf{0 . 2 0}$ & $\mathbf{0 . 4 0}$ & $2.534 \mathrm{E}-01$ & $3.065 \mathrm{E}-01$ & $3.090 \mathrm{E}-01$ & $2.928 \mathrm{E}-01$ & $2.872 \mathrm{E}-01$ \\
$\mathbf{6}$ & $\mathbf{0 . 4 0}$ & $\mathbf{0 . 8 0}$ & $1.371 \mathrm{E}-01$ & $1.543 \mathrm{E}-01$ & $1.508 \mathrm{E}-01$ & $1.393 \mathrm{E}-01$ & $1.537 \mathrm{E}-01$ \\
$\mathbf{7}$ & $\mathbf{0 . 8 0}$ & $\mathbf{1 . 2 0}$ & $2.231 \mathrm{E}-02$ & $2.090 \mathrm{E}-02$ & $1.733 \mathrm{E}-02$ & $1.604 \mathrm{E}-02$ & $2.264 \mathrm{E}-02$ \\
$\mathbf{8}$ & $\mathbf{1 . 2 0}$ & $\mathbf{1 . 7 0}$ & $5.800 \mathrm{E}-03$ & $3.853 \mathrm{E}-03$ & $3.260 \mathrm{E}-03$ & $3.999 \mathrm{E}-03$ & $4.057 \mathrm{E}-03$ \\
$\mathbf{9}$ & $\mathbf{1 . 7 0}$ & $\mathbf{2 . 5 0}$ & $1.203 \mathrm{E}-03$ & $8.958 \mathrm{E}-04$ & $9.618 \mathrm{E}-04$ & $9.482 \mathrm{E}-04$ & $1.108 \mathrm{E}-03$ \\
$\mathbf{1 0}$ & $\mathbf{2 . 5 0}$ & $\mathbf{4 . 0 0}$ & $2.696 \mathrm{E}-04$ & $1.676 \mathrm{E}-04$ & $2.199 \mathrm{E}-04$ & $1.456 \mathrm{E}-04$ & $2.485 \mathrm{E}-04$ \\
$\mathbf{1 1}$ & $\mathbf{4 . 0 0}$ & $\mathbf{6 . 0 0}$ & $5.125 \mathrm{E}-05$ & $4.360 \mathrm{E}-05$ & $4.369 \mathrm{E}-05$ & $3.738 \mathrm{E}-05$ & $4.680 \mathrm{E}-05$ \\
$\mathbf{1 2}$ & $\mathbf{6 . 0 0}$ & $\mathbf{8 . 0 0}$ & $1.604 \mathrm{E}-05$ & $1.546 \mathrm{E}-05$ & $1.445 \mathrm{E}-05$ & $1.220 \mathrm{E}-05$ & $1.559 \mathrm{E}-05$ \\
$\mathbf{1 3}$ & $\mathbf{8 . 0 0}$ & $\mathbf{1 0 . 0 0}$ & $6.455 \mathrm{E}-06$ & $6.868 \mathrm{E}-06$ & $6.946 \mathrm{E}-06$ & $4.686 \mathrm{E}-06$ & $6.707 \mathrm{E}-06$ \\
$\mathbf{1 4}$ & $\mathbf{1 0 . 0 0}$ & $\mathbf{1 7 . 0 0}$ & $4.090 \mathrm{E}-06$ & $2.984 \mathrm{E}-06$ & $3.184 \mathrm{E}-06$ & $2.599 \mathrm{E}-06$ & $3.086 \mathrm{E}-06$ \\
\hline
\end{tabular}

Table 2. Assembly FE DIA100, R53; 200 gpd, H-det measurement integral values (energy range is in $\mathrm{MeV}$ ).

\begin{tabular}{cccccccc}
\hline \multicolumn{4}{c}{ Energy Range } & \multicolumn{3}{c}{ Libraries used for MCNP Calculation } \\
\hline No. & from & to & EXP & ENDF & BROND & JENDL & JEFF \\
\hline $\mathbf{0}$ & $\mathbf{0 . 0 1}$ & $\mathbf{1 . 2 9}$ & $\mathbf{1 . 0 4 4 E}+\mathbf{0 0}$ & $\mathbf{1 . 0 7 8 E}+\mathbf{0 0}$ & $\mathbf{1 . 0 6 4 E}+\mathbf{0 0}$ & $\mathbf{1 . 0 6 4 E}+\mathbf{0 0}$ & $\mathbf{1 . 1 1 4 E}+\mathbf{0 0}$ \\
\hline $\mathbf{1}$ & $\mathbf{0 . 0 1}$ & $\mathbf{0 . 0 3}$ & $1.533 \mathrm{E}-01$ & $1.387 \mathrm{E}-01$ & $1.374 \mathrm{E}-01$ & $1.401 \mathrm{E}-01$ & $1.505 \mathrm{E}-01$ \\
$\mathbf{2}$ & $\mathbf{0 . 0 3}$ & $\mathbf{0 . 0 8}$ & $7.075 \mathrm{E}-02$ & $6.358 \mathrm{E}-02$ & $6.030 \mathrm{E}-02$ & $6.529 \mathrm{E}-02$ & $6.610 \mathrm{E}-02$ \\
$\mathbf{3}$ & $\mathbf{0 . 0 8}$ & $\mathbf{0 . 0 9}$ & $4.185 \mathrm{E}-02$ & $4.142 \mathrm{E}-02$ & $4.100 \mathrm{E}-02$ & $4.365 \mathrm{E}-02$ & $4.300 \mathrm{E}-02$ \\
$\mathbf{4}$ & $\mathbf{0 . 0 9}$ & $\mathbf{0 . 1 5}$ & $1.576 \mathrm{E}-01$ & $1.326 \mathrm{E}-01$ & $1.325 \mathrm{E}-01$ & $1.460 \mathrm{E}-01$ & $1.588 \mathrm{E}-01$ \\
$\mathbf{5}$ & $\mathbf{0 . 1 5}$ & $\mathbf{0 . 2 0}$ & $1.047 \mathrm{E}-01$ & $9.654 \mathrm{E}-02$ & $9.498 \mathrm{E}-02$ & $1.018 \mathrm{E}-01$ & $1.071 \mathrm{E}-01$ \\
$\mathbf{6}$ & $\mathbf{0 . 2 0}$ & $\mathbf{0 . 2 5}$ & $6.486 \mathrm{E}-02$ & $6.643 \mathrm{E}-02$ & $6.425 \mathrm{E}-02$ & $6.559 \mathrm{E}-02$ & $6.637 \mathrm{E}-02$ \\
$\mathbf{7}$ & $\mathbf{0 . 2 5}$ & $\mathbf{0 . 2 9}$ & $7.799 \mathrm{E}-02$ & $8.494 \mathrm{E}-02$ & $8.211 \mathrm{E}-02$ & $8.028 \mathrm{E}-02$ & $8.013 \mathrm{E}-02$ \\
$\mathbf{8}$ & $\mathbf{0 . 2 9}$ & $\mathbf{0 . 3 3}$ & $9.448 \mathrm{E}-02$ & $1.354 \mathrm{E}-01$ & $1.333 \mathrm{E}-01$ & $1.241 \mathrm{E}-01$ & $1.209 \mathrm{E}-01$ \\
$\mathbf{9}$ & $\mathbf{0 . 3 3}$ & $\mathbf{0 . 4 1}$ & $8.185 \mathrm{E}-02$ & $1.046 \mathrm{E}-01$ & $1.154 \mathrm{E}-01$ & $1.081 \mathrm{E}-01$ & $1.043 \mathrm{E}-01$ \\
$\mathbf{1 0}$ & $\mathbf{0 . 4 1}$ & $\mathbf{0 . 5 2}$ & $5.090 \mathrm{E}-02$ & $5.296 \mathrm{E}-02$ & $5.077 \mathrm{E}-02$ & $4.867 \mathrm{E}-02$ & $5.701 \mathrm{E}-02$ \\
$\mathbf{1 1}$ & $\mathbf{0 . 5 2}$ & $\mathbf{0 . 7 8}$ & $1.146 \mathrm{E}-01$ & $1.317 \mathrm{E}-01$ & $1.279 \mathrm{E}-01$ & $1.171 \mathrm{E}-01$ & $1.271 \mathrm{E}-01$ \\
$\mathbf{1 2}$ & $\mathbf{0 . 7 8}$ & $\mathbf{1 . 0 6}$ & $2.379 \mathrm{E}-02$ & $2.257 \mathrm{E}-02$ & $1.930 \mathrm{E}-02$ & $1.665 \mathrm{E}-02$ & $2.585 \mathrm{E}-02$ \\
$\mathbf{1 3}$ & $\mathbf{1 . 0 6}$ & $\mathbf{1 . 2 9}$ & $7.426 \mathrm{E}-03$ & $6.759 \mathrm{E}-03$ & $5.311 \mathrm{E}-03$ & $6.393 \mathrm{E}-03$ & $6.690 \mathrm{E}-03$ \\
\hline
\end{tabular}

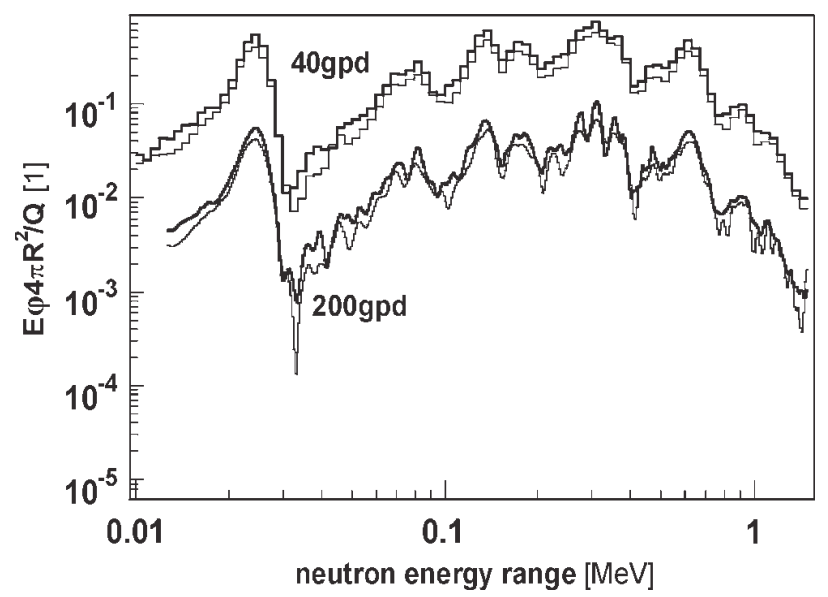

Fig. 6. Assembly: FE DIA100, R150 and R53, 40 gpd and 200 gpd. Measurement by H-det. R53 - thick, 200 gpd (diminished by 10).

\section{Normalisation and smoothing of results}

The result of spectra calculation and measurement $\varphi(\mathrm{E})$ is normalised in the following way

$$
4 \pi \mathrm{R}^{2} \varphi(\mathrm{E}) / \mathrm{Q}[1 / \mathrm{MeV}]
$$

where $\mathrm{R}$ is the distance between detector and neutron source (centre to centre) and $\mathrm{Q}[1 / \mathrm{s}]$ is neutron source emission.
Table 3. Assembly FE DIA100, R150; and R53; 200 gpd, H-det measurement - integral values (energy range is in $\mathrm{MeV}$ ). Data are presented as the Calculation/Experiment.

\begin{tabular}{|c|c|c|c|c|c|c|c|}
\hline \multicolumn{4}{|c|}{ Energy Range } & \multicolumn{4}{|c|}{ Libraries used for MCNP Calculation } \\
\hline No. & from & to & EXP & ENDF & BROND & JENDL & JEFF \\
\hline \multirow[t]{2}{*}{$\mathbf{0}$} & 0.01 & 1.29 & $\mathbf{R 5 3}$ & 1.033 & 1.019 & 1.019 & 1.067 \\
\hline & & & R100 & 1.029 & 1.017 & 1.011 & 1.059 \\
\hline \multirow[t]{2}{*}{1} & 0.01 & 0.03 & $\mathbf{R 5 3}$ & 0.905 & 0.896 & 0.914 & 0.982 \\
\hline & & & R100 & 0.887 & 0.879 & 0.902 & 0.974 \\
\hline \multirow[t]{2}{*}{2} & 0.03 & 0.08 & R53 & 0.899 & 0.852 & 0.923 & 0.934 \\
\hline & & & R100 & 0.907 & 0.860 & 0.930 & 0.942 \\
\hline \multirow[t]{2}{*}{3} & 0.08 & 0.09 & R53 & 0.990 & 0.980 & 1.043 & 1.028 \\
\hline & & & R100 & 0.979 & 0.970 & 1.029 & 1.015 \\
\hline \multirow[t]{2}{*}{4} & 0.09 & 0.15 & $\mathbf{R 5 3}$ & 0.841 & 0.841 & 0.926 & 1.007 \\
\hline & & & $\mathbf{R} 100$ & 0.831 & 0.832 & 0.916 & 1.000 \\
\hline \multirow[t]{2}{*}{5} & 0.15 & 0.20 & R53 & 0.922 & 0.907 & 0.972 & 1.023 \\
\hline & & & R100 & 0.898 & 0.885 & 0.944 & 0.998 \\
\hline \multirow[t]{2}{*}{6} & 0.2 & 0.25 & R53 & 1.024 & 0.991 & 1.011 & 1.023 \\
\hline & & & $\mathbf{R} 100$ & 1.102 & 1.07 & 1.082 & 1.095 \\
\hline \multirow[t]{2}{*}{7} & 0.25 & 0.29 & R53 & 1.089 & 1.053 & 1.029 & 1.027 \\
\hline & & & R100 & 1.103 & 1.069 & 1.034 & 1.030 \\
\hline \multirow[t]{2}{*}{8} & 0.29 & 0.33 & $\mathbf{R 5 3}$ & 1.433 & 1.411 & 1.314 & 1.280 \\
\hline & & & R100 & 1.423 & 1.401 & 1.289 & 1.255 \\
\hline \multirow[t]{2}{*}{9} & 0.33 & 0.41 & $\mathbf{R 5 3}$ & 1.277 & 1.409 & 1.321 & 1.275 \\
\hline & & & R100 & 1.198 & 1.323 & 1.229 & 1.181 \\
\hline \multirow[t]{2}{*}{10} & 0.41 & 0.52 & R53 & 1.041 & 0.997 & 0.956 & 1.120 \\
\hline & & & R100 & 1.065 & 1.024 & 0.976 & 1.141 \\
\hline \multirow[t]{2}{*}{11} & 0.52 & 0.78 & R53 & 1.15 & 1.117 & 1.022 & 1.109 \\
\hline & & & $\mathbf{R} 100$ & 1.146 & 1.116 & 1.020 & 1.097 \\
\hline \multirow[t]{2}{*}{12} & 0.78 & 1.06 & R53 & 0.949 & 0.811 & 0.700 & 1.086 \\
\hline & & & R100 & 0.968 & 0.812 & 0.712 & 1.091 \\
\hline \multirow[t]{2}{*}{13} & 1.06 & 1.29 & $\mathbf{R 5 3}$ & 0.910 & 0.715 & 0.861 & 0.901 \\
\hline & & & R100 & 0.941 & 0.719 & 0.8177 & 0.916 \\
\hline
\end{tabular}

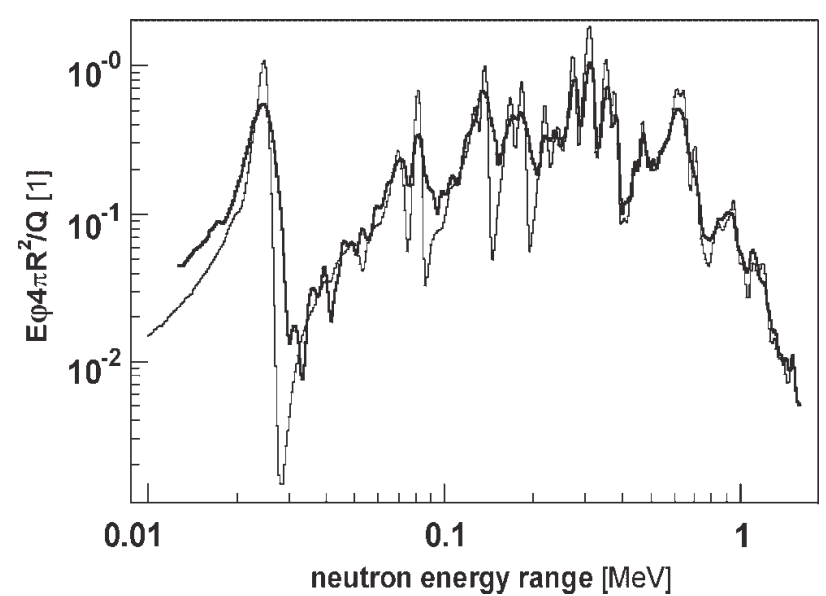

Fig. 7. Assembly: FE DIA100, R53, 200 gpd. Measurement by H-det - thick. Calculation by ENDF/B-VI.8 - thin.

Quantity depicted in the figures has the following form and dimension

$$
4 \pi \mathrm{R}^{2} \mathrm{E} \varphi(\mathrm{E}) / \mathrm{Q}[1]
$$

The integral values presented in tables are also with dimension of 1.

The calculated spectra were smoothed by Gaussian with constant percentage resolution $\Delta$ of FWHM: $\Delta=13 \%$ for $40 \mathrm{gpd}$ and $\Delta=4 \%$ for $200 \mathrm{gpd}$. 


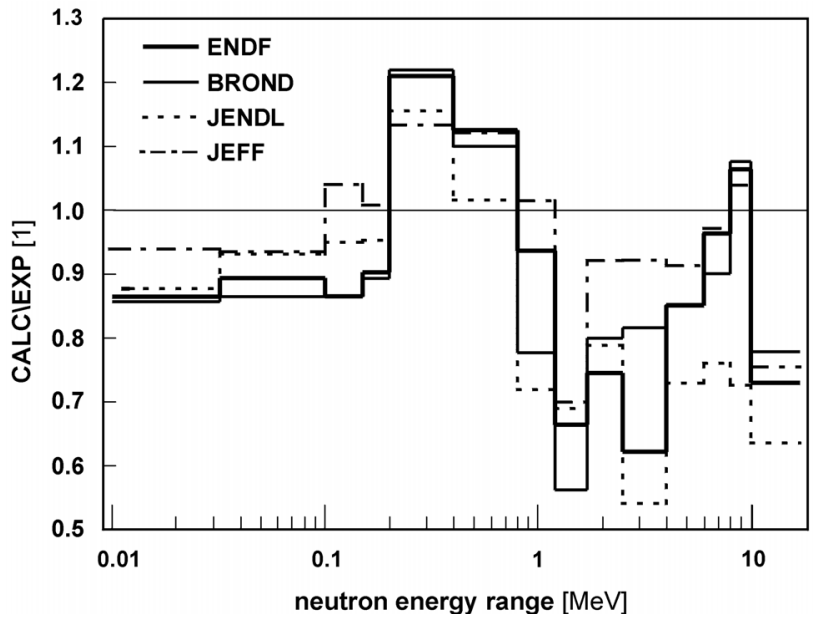

Fig. 8. Assembly: FE DIA100, R150, 40 gpd. Measurement by H-det and stilbene. Comparison of calc. relative to EXP (table 1).

\section{Uncertainties}

MCNP code gives only statistical uncertainties which are smaller then $5 \%$ for $\mathrm{En}<6 \mathrm{MeV}, 40$ gpd and $10^{8}$ histories.

Statistical uncertainties of $\mathrm{H}$-detector measurements are calculated and represent the values about 3\% for spectrum maximum for FE DIA100, R150 assembly and about $1 \%$ for FE DIA100, R53 assembly. These uncertainties were assessed for $40 \mathrm{gpd}$.

Statistical uncertainties of integral values are adequately calculated. Uncertainties based on methodology of measured spectra evaluation (like energy calibration, etc.) are estimated by authors to be approx. $1-2 \%$ for energy range $0.15-0.8 \mathrm{MeV}$ and $3-7 \%$ for energy range $0.01-0.15 \mathrm{MeV}$.

Uncertainties of stilbene measurements are estimated by authors to be $7-15 \%$ for energy range $1-17 \mathrm{MeV}$.

Estimation of another existing uncertainties (like of the source emission, efficiency of detectors, etc.) is out of scope of this article.

\section{Results of measurement and calculations}

Two types of experimental results are presented:

- Assembly FE DIA100, R150, H-detector and stilbene measurement, binding energy for those methods is 1.2 MeV,
- Assembly FE DIA100, R53 (measurement on the surface), H-detector only.

Comparison of the measured and calculated results is presented in figures 2-8 and tables 1-3.

The measurement on the surface in $R=53 \mathrm{~cm}$ seems to be reasonable for obtaining better statistics of experiment.

\section{Conclusion}

The calculations performed in scale 40 gpd overestimate measured spectra (by $\mathrm{H}$-det and stilbene) in region around $0.3 \mathrm{MeV}$ by about $10-20 \%$ and also around $0.6 \mathrm{MeV}$ by about $10 \%$ (see table 1 and fig. 8). The calculations performed in scale 200 gpd overestimate measured spectra (by H-det and stilbene) in region around $0.3 \mathrm{MeV}$ by about $30-40 \%$ (see table 2).

The calculations in the energy region above $1 \mathrm{MeV}$ underestimate measured spectrum (by stilbene) by about $20-40 \%$ depending on the library used (see table 1 and fig. 8).

The differences, between measurement and calculations (performed in this case ENDF/B-VI), described above, were observed also on the pure iron spheres of diameters 20, 30 and $50 \mathrm{~cm} \mathrm{[3].}$

This work was prepared under the project No. 1H-PK2/05 of Ministry of Trade and Industry of the Czech Republic and under the project of the Research Center Rez Ltd. of the Czech Republic.

\section{References}

1. Yu.I. Kolevatov, V.P. Semenov, L.A. Trykov, Neutron and gamma spectrometry in radiation physics, Energoatomizdat, Moscow, Russia (1990) (in Russian).

2. B. Jansky, P. Otopal, E. Novak, Data for calculation of the neutron and gamma leakage spectra from iron and water spheres with Cf-252 neutron source in centre, NRI Report UJV-11506, NRI Rez, November 2000.

3. B. Jansky, E. Novak, Z. Turzik, J. Kyncl, F. Cvachovec, P. Cuda, J. Kluson, L.A. Trykov, V.S. Volkov, Neutron and gamma leakage spectra measurements and calculations in pure iron benchmark assembly with Cf-252 neutron source, in International Conference on Nuclear data for Science and Technology, ND 2001, Tsukuba, Ibaraki, Japan, 2001, J. Nucl. Sci. Techol., Suppl. 2 (August 2002). 